\title{
ABSTRACTS OF PATENT SPECIFICATIONS
}

\author{
(Specially abstracted for the Journal by W. O. Manning, F.R.Ae.S.)
}

Regular abstracts of Patent Specifications received by the Society will be published in future in the Journal. It should be noted that these abstracts are specially compiled by Mr. W. O. Manning, F.R.Ae.S., for the Journal and are only of those actually received and subsequently bound in volume form for reference in the library. These volumes extend from the earliest aeronautical patents to date, and form a unique collection of the efforts which have been made to conquer the air.

The Council accept no responsibility whatever for the accuracy of the abstracts and in any case of doubt the full patent can be consulted when necessary in the library of the Society.

These abstracts are compiled by permission of the Controller of His Majesty's Stationery Office. Official Group Abridgments can be obtained from the Patent Office, 25, Southampton Buildings, London, W.C.2, either sheet by sheet as issued on payment of a subscription of $5 \mathbf{s}$. per group volume or in bound volumes 2s. each, and copies of full specifications can be obtained from the same address, price Is. each.

\section{Aerodynamics, Stability and Controllability}

397,805. Improvements in or Relating to Automatic Steering Apparatus for Aircraft. Askania-Werke Aktiengesellschaft vormals Centralwerkstatt Dessau und Carl Bambergfriedenau. Kaiserallee 87/88 Berlin-Friedenau, Germany. Convention date (Germany), April 2oth, 1932.

The statement is made that when an aircraft is inclined with reference to its longitudinal axis, by, for instance, a gust of wind, it deviates from its course, and further, that the course is influenced by the inclined positions which an aircraft must assume on a curve. The influences which the inclined position of an aircraft exerts on the course steering make themselves noticeable in an objectionable manner, particularly in the case of automatic course steering.

It is proposed to overcome this difficulty by arranging that the lateral steering is additionally influenced by an impulse derived from the turning velocity of the aircraft about its longitudinal axis. The apparatus is to be adjustable so as to suit different aircraft and it is stated that if the lateral steering is influenced by a gyroscope with two degrees of freedom and axis of rotation parallel with the aircraft transverse axis, the invention can be so carried out and applied that the influence derived from the turning velocity about the longitudinal axis is applied against the precession influence of the gyroscope. The impulse to be derived from the turning velocity about the longitudinal axis can also be derived from a gyroscope with two degrees of freedom. The precessional effects of both gyroscopes can be caused to act on a relay. The drawing shows a compressed air relay operated gyroscopically. 
398,069. Aeroplanes with Auto-stable Arrangements of Planes. Albessard, J., 31, Rue du Laos, Paris, France. December r $3^{\text {th, }}$ 1932. No. $35,35^{2}$.

It is proposed to take advantage of the upward velocity of the air on the outer sides of the wing tip vortices of an ordinary aeroplane wing by placing additional wings behind the main wing tips so that they operate in these upward currents. This arrangement is claimed to increase the safety of aircraft and also to lead to easy control, impossibility of nose-diving, side-slipping, etc., and also to cause resistance to rolling and pitching in squalls.

The drawings show numerous arrangements of aircraft wings constructed in accordance with the specification.

399,048. Improvements in or Relating to Aeroplanes having Surfaces Variable During Flight. Gerin, J., 24, Rue de la Tourelle, Boulogne-sur-Seine, France. Convention date (France), December 9th, 1931.

This refers to the type of variable area wing in which the area is varied by extending the chord of the wing. It is stated that the fixed portion of the wing is adapted to lift the aeroplane at high speeds, while the portion to be extended out has a great curvature in order to have a very high lifting action.

\section{Aeroplanes, Construction}

397,497. Improvements in or Relating to Aircraft Wheel Brakes. The India Rubber, Gutta Percha and Telegraph Works Co., Ltd., Aldwych House, Aldwych, London, W.C.2, and Tarris, F. J., of the Company's Works at Silvertown, London, E.I6. February 23rd, 1932. No. 5,420.

Aircraft wheel brakes are described so that the wheels may be braked simultaneously for checking the speed of the aircraft or differentially for steering purposes. When the brakes are used for steering they are operated by the pilot's rudder bar.

The brakes are operated by compressed air and there are two apparata each containing two cylinders. These cylinders are operated through linkage which, in turn, is operated by the rudder bar. These two apparata are placed one each side of the rudder bar and cause the brakes to be applied on either wheel so that the steering of the aircraft on the ground is in the normal direction. The two cylinders act so as to cause the air pressure to be raised or lowered in each wheel brake as required.

The air pressure is supplied from an outside source and an arrangement is described, operated by one lever, by which the apparatus can be cut out or cut in as desired by the pilot.

397,895. Improvements in Aircraft Wheel Braking Systems. Dunlop Rubber Co., Ltd., 32, Osnaburg Street, London, N.W.r. Goodyear, E. F., Wright, J., and Trevaskis, H., of the Company's Works at Foleshill, Coventry. December 2nd, 1931. No. 33,370.

This wheel brake arrangement is stated to enable delicate degrees of brake application to be effected with minimum effort. The braking force is transmitted by means of compressed air, the distribution of the compressed air to the two wheels being effected by an arrangement consisting of two relays arranged in a $\mathrm{V}$. The relays are controlled by links operated from a sliding member placed about in the angle of the $\mathrm{V}$, and this sliding member may be displaced radially by a connection to the rudder bar so that one relay is moved more than the other when the rudder bar is displaced, thereby transmitting a differential pressure to the brakes. The sliding member is controlled from the control stick of the aeroplane by means of a short lever connected to the sliding member by means of a Bowden cable, or by rod and link work. 
397,896. Aeroplane Brakes and their Controls and Valves Therefor. Dunlop Rubber Co., Ltd., 32, Osnaburg Street, London, N.W.I. Goodyear, E. F., Wright, J., and Trevaskis, H., of the Company's Works at Foleshill, Coventry. December 2nd, I93I, No. 33,37I, and July I6th, 1932, No. 20,184 .

The specification deals with relay valves and the arrangement thereof for the purpose of operating aircraft brakes together and differentially. Applications 33,370/31 (Serial No. 397,895) and 33,372/31 (Serial No. 397,897) are referred to.

There is described a method of operating relay valves for compressed air brakes by arranging them in a V and controlling them by means of a sliding member located in approximately the angle of the $V$. This sliding member may be displaced radially by means of a connection to the rudder bar so that the degree of operation of the relays may be varied differentially, causing differential application of the brakes.

The specification describes in detail the type of relay it is proposed to use, a yielding diaphragm, in addition to inlet and exhaust valves being operated by the control. This is arranged so as to enable the air pressure distributed to the two wheels to be varied in accordance with the control movement used by the pilot.

397,897. Aeroplane Brakes and their Control. The Dunlop Rubber Co., Ltd., 32, Osnaburg Street, London, N.W.r. Goodyear, E. F., Wright, J., and Trevaskis, H., of the Company's Works at Foleshill, Coventry. December 2nd, 1931. No. 33,372.

Pneumatically operated aircraft brakes are described in which the relays are arranged in the form of $\mathrm{a} \mathrm{V}$ and are operated by link gear from a point approximately in the angle of the $V$. This operation is effected by means of a sliding member in a guideway capable of being displaced radially so that the two relays are differentially actuated, with the result that the air pressure is differentially distributed to the aircraft wheels. The radial displacement of the sliding member and guideway may be effected by a connection to the rudder bar, while the operation of the sliding member in the guideway is controlled by the pilot by means of a small lever attached to the control stick.

Reference is made to Applications 33,370/3I (Serial No. 397,895), 33,37 $1 / 3^{\mathrm{I}}$ and $20,184 / 32$ (Serial No. 397,896).

398,892. Fluid Pressure Brakes for Aircraft Wheels. Vickers (Aviation), Ltd., and Duncan, T. S., both of Weybridge Works, Byfleet Road, Weybridge. March 24th, 1932. No. 8,785.

It is stated that in the case of wheel brakes for aircraft means must be provided to enable the braking force to be applied differentially to the wheels so that the machine may be steered on the ground. At the same time the maximum braking power must be limited so as to remove all risk of the machine overturning when the brakes are applied. It is, however, necessary to provide greater power when the aircraft is stationary to permit of the engines being run up while the aircraft is on the ground.

This specification describes a method by which fluid pressure can be distributed to the wheel brakes through pedal controlled reducing valves, so that limited braking pressure corresponding to the depression of the pedals is produced differentially in the wheels. At the will of the pilot the full pressure may be applied directly to the brakes for parking or running up engines.

The arrangement shown in the drawings consists of a reducing valve controlled by a diaphragm which is acted on by the pedal through a spring. This diaphragm controls both inlet and exhaust valves, and the pressure distributed to the brakes depends on the pressure applied to the pedal. 
There is a device operated by a lever which enables the pilot to cut out the reducing valve and admit pressure directly to the brakes, this is used for parking purposes and when it is desired to run up the engines.

397,964. Improvements in or Relating to Aeroplanes. Airspeed, Ltd, and Tiltman, A. H., both of Piccadilly, York, Yorkshire. April 27th, 1932. No. 12,088 .

The specification refers to a retractable undercarriage arranged to be folded into an aeroplane wing. The undercarriage structure consists of an approximately vertical shock-absorber strut, a diagonal strut for lateral support, running inwards and upwards from the stub axle carrying the wheel and another strut running backwards and upwards to the wing from the axle for longitudinal support. One such structure is used for each wheel in a normal aeroplane.

The retractable arrangement consists in introducing into the strut running backwards a joint similar to that of a perambulator hood support. The point where the joint is fitted in the strut is attached movably to a hydraulic ram, the other end of which is attached to the wing at a point higher than that of the strut attachment. On introducing pressure into the ram in such a direction as to shorten it, the undercarriage is caused to retract into the wing. An arrangement is referred to whereby the aeroplane may land without severe injury with the undercarriage retracted.

398,244. Tailless Aeroplane. Langguth, W., Stuttgarter-Strasse am Walde, Böblingen, i/Worttemberg, Germany. March 1 Ith, I932. No. 7,303 .

In order to reduce the bending movements of the wing spars of an aeroplane, thereby saving weight, the inventor proposes to distribute the load, in combination with the weight of the wings, over the length of the wings approximately in the same proportion as the lift forces. An arrangement by which at least one spar in each wing is adapted to be used as a magazine or chamber for the useful load is also claimed.

The drawing shows an aeroplane consisting simply of an aeroplane wing, which is arranged in $V$ form in the plan.

398,4II. Retractable Landing Gear for Aircraft. Dornier Metallbauten G.M.B.H. and Dr. Dornier, both of Friedrichshafen, Lake Constance, Germany, Convention date (Germany),. April 26th, 1932. Application date (United Kingdom), February 23rd, 1933. No. 5,59r.

This is a retractable undercarriage for high wing monoplanes, the undercarriage being drawn into the fuselage. A vertically disposed screw-threaded spindle is arranged in the fuselage and the fulcrums of the movable members of the undercarriage are carried by a nut adapted to travel on the screwed spindle so that when the nut is screwed to the top of the spindle the undercarriage is wholly or partly within the fuselage. The undercarriage in the opened out position may be secured in position by means of ropes, or the like, secured at one end near the hub of the landing wheels, at the other end to the wing of the aircraft, being arranged to be tightly stretched when the landing gear is in its lowest position.

396,956. Improvements in or Relating to Undercarriages or Landing Gear for Aircraft. Dornier Metallbauten G.M.B.H. and Dr. Ing. C. Dornier, both of Friedrichshafen, Lake Constance, Germany. Convention date, December 8th, 1931.

This folding undercarriage is of the type that projects laterally from the lower part of a fuselage, and the wheels and axles are arranged to fold in a direction transverse to the longitudinal axis of the aeroplane, the wheels being 
approximately parallel with each other during the folding process. The final result is that the wheels lie flat in recesses in the sides of the fuselage.

A frame is fitted within the fuselage which is fitted with slots which act as guides during the displacement of the undercarriage. This frame or guiding device is a rigid member and is forced by springs or other resilient devices into open V-shaped bearings which are positioned as far as possible from the centre line of the aircraft. Locking pawls and a rope raising and lowering device are also described.

\section{Aircraft, Military}

397,433. Device for the Feeding of Cartridges in Automatic Firearms. Societe Anonyme des Anciens Etablissements Hotchkiss et Cie, 6, Route de Gonesse, St. Denis (Seine), France. Convention date (France), January 2 1st, 1933 .

This specification refers to the feeding of cartridges into machine-guns, especially when situated in the wings of aircraft. It is pointed out that the tractive effort required to draw a long band of cartridges into the gun is considerable.

The inventors propose to overcome this difficulty by disposing the cartridge band in the form of a hairpin, the bend consisting of a large pulley. The band is sloped down from the top of the pulley to the gun so that the feed is assisted by gravity. The degree of the slope is made as great as possible consistent with the thickness of the wing in which it is placed.

\section{Airscrews}

397,027. Improvements in Endless-Track Propellers for Marine Vessels or Aircraft. Phillipp, H., Paracelsusstrasse 13, Salzburg, Austria. Date, February 8th, 1933. No. 3,827.

This describes a form of paddle propeller in which the paddles are connected to an endless chain instead of to a wheel. The specification describes means by which the paddles can be brought into the working position, secured, and again released into a freely swinging position where the resistance is nearly eliminated. It is stated that the arrangement can be used when the paddle chain is entirely submerged.

\section{Autogiros}

397,120. Improvements in Flying Machines and in Apparatus for the Propulsion of Fluids. Pitter, W. C., 59, Bower Hill, Epping. February I $5^{\text {th, }}$ 1932. No. 4,43 .

This arrangement is described as a modification of the "Autogiro," and use is made of radially arranged wings freely rotatable, as heretofore, about a vertical axis; the wings, however, being so constructed that they will be transversely flexible or movable each about its own longitudinal axis. The radial wings are described as being flapped or oscillated to and from the vertical axis about hinges or pivots which are carried by a freely rotatable sleeve. It is stated that by arranging the wings near the same plane and operating them in such a manner that some are oscillating upwards while others are oscillating downwards, the descending wings will meet a supporting current of air caused by the wings oscillating upwards. 


\section{Balloons}

397,347. Improvements in Captive Balloons. Letourneur, J., 75, Rue de la Parcisse, Versailles (Seine et Oise), France. Convention date (France), November $27^{\text {th }}$, 1931 .

This deals with a method of constructing the fins of kite balloons, which fins are kept extended by means of air introduced by scoops. It is pointed out that the geometrical surfaces that it is possible to obtain with a fabric held taut by internal pressure are limited, as the surface has to be under tension at all points. The fin proposed has the general form of the usual type, but its exterior contour is composed of a cylindrical surface. The space between the envelope and this surface is filled with portions of cylinders of revolution, the radii of which decrease towards the rear.

\section{Dopes and Fabrics}

398,156. Improvements in or Relating to the Coating of Fabrics. E. I. Du Pont de Nemours \& Co., Wilmington, Delaware, U.S.A. Convention date (U.S.A.), December $3^{\text {rd }}$ 1930. Application date (in United Kingdom),

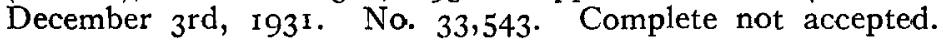

This specification deals with the composition of dopes for coating aircraft fabrics, loud speaker cones, etc., and it is proposed to substitute cellulose ethers, such as benzyl cellulose, ethyl cellulose, and crotyl cellulose, for the more usual cellulose acetate and cellulose nitrate in the composition of these dopes.

A suggested formula for a first coat is-

Benzyl cellulose ... ... ... ...

Denatured alcohol $\quad \ldots \quad \ldots \quad \ldots$

Toluol

A suggested formula for a top coat is-

Benzyl cellulose $\quad \ldots \quad \ldots \quad \ldots$

$\begin{array}{lllll}\text { Pigment } & \ldots & \ldots & \text { I } 4.5 \text { parts by weight. }\end{array}$

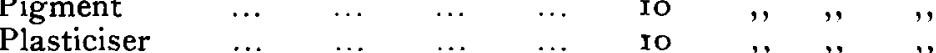

Toluol

$\begin{array}{lllllllll}\text { Toluol } & \ldots & \ldots & \ldots & \ldots & \ldots & 40 & ,, & ,\end{array}$

$\begin{array}{llllllllll}\text { Xylol } & \ldots & \ldots & \ldots & \ldots & \ldots & \mathbf{1} 2 & , & , & ,\end{array}$

Glycol monomethyl ether $\ldots \quad \ldots \quad 6 \quad$, , , , ,"

Denatured alcohol $\ldots \quad \ldots \quad \ldots \quad$ 17.5 , , , , ,

A further suggested formula is given for a top coat containing cellulose acetate in addition to benzyl cellulose.

\section{Engines}

392,949. Improvements in Engine Mountings. Trott, R. S., 704, Equitable Building, Denver, Colorado, U.S.A. November I6th, I93I. No. $3^{1,670 .}$

This is a mounting intended to smooth out the variable torque of a petrol engine and so to prevent vibration occurring. It consists of providing two points of support for the engine, including, if desired, the gearbox. These points of support are arranged longitudinally and take the weight of the power plant, one at least of them is to be of non-metallic and resilient material and permitting of a movement of the unit with reference to the frame.

A separate resilient connection is made to the frame for the purpose of transmitting torque. Various types of resilient connections are described and shown in the drawing, some depending on rubber and others on spring devices. A drawing is also given showing the application of the mounting to an aero engine. 


\section{Jet Propulsion}

397,992. Devices for Propelling by Reaction. Rey, J. A., 30, Rue de Versailles, Viroflay (Seine et Oise), France. Convention date (France), June 25th, 1931.

A jet propulsion arrangement is described, stated as being suitable for the propulsion of rockets, vehicles, ships or the like. The propulsion is effected by means of the reaction of ejected fluids in which the propelling fluid is allowed to expand in an enlarging passage and draws in additional fluid in one or two stages prior to ejection. It is stated that more than two fluids can be used; for example, in the propulsion of a ship it is proposed to use steam to draw air into the first duct, the mixture of steam and air being used in a second duct into which it draws sea water.

The drawing shows a taper nozzle provided with lateral passages for the introduction of the additional fluid or fluids. 